\section{External Habits Formation and the Environment}

\section{Fatma Safi}

University of Sfax

Faculty of Economics and Management, Department of Economics, Tunisia fatma_safi@yahoo.fr

\begin{abstract}
The present paper presents a standard overlapping generations model with external habits formation and environmental quality in the utility function. Our main objective is to study the impact of external habits on capital accumulation and environmental quality on the intertemporal competitive equilibrium. We notice that striving for status leads to environment worsening and capital increasing when the cohort size is large.
\end{abstract}

Keywords: external habits, overlapping generations, environmental quality

\section{Introduction}

The economic theory states that an individual will buy a product once the intrinsic satisfaction of the actual product surpasses the price of the product, although, this does not take into consideration the status a certain good will provide them with. Mostly, the behavior of the consumer is affected by much more than utility maximization. Consumers consider the price of the product, its quality, how it works, what it represents, and many other aspects that are not simple to determine, and personal to each individual in order to evaluate a good and its utility. The consumer will also view, before making a purchasing decision, the consumption habits of his or her peers. The consumption reference levels generate a consumption externality. The consumer forms then external habits by driving for social position.

External habit formation has long been considered an essential factor of human behavior. Status concern is another characteristic feature of consumption decisions. It influences the analysis of the relationship between consumption decisions and their associated externalities regarding environmental quality. The concept of external habit formation postulates that if the agent's utility is influenced by either average current or average lagged consumption in the economy, then the agent is "keeping up with the Joneses" or "catching up with the Joneses", respectively and the agent is "outward-looking" (de la Croix, 1996; de la Croix \& Michel, 1999). With external habit formation, the build-up level of average past consumption in the economy at large influences the current utility of an individual consumer. The outward habit is a kind of intertemporal consumption externality, and the consumer does not internalize outward habits when making his optimal decision. Using household-level data, Hung et al. (2015) supports the presence of temptation features and self-control problems.
ORIGINAL SCIENTIFIC PAPER

RECEIVED: OCTOBER 2020

REVISED: FEBRUARY 2020

ACCEPTED: MARCH 2021

DOI: 10.2478/ngoe-2021-0001

UDK: 364.68:005.931

JEL: D62, D91, E21, Q50

Citation: Safi, F. (2021). External Habits Formation and the Environment. Naše gospodarstvo/Our Economy, 67(1), 1-12. DOI: 10.2478/ngoe-2021-0001
NG

NAŠE GOSPODARSTVO OUR ECONOMY

\begin{tabular}{l|l|l} 
Vol. 67 & No. 1 & 2021 \\
\hline
\end{tabular}

pp. 1-12 
For a long time, these kinds of "extended preferences", following Becker's (1997) terminology, have been cut off from environmental issues. However, recently, several authors have introduced habits in pollution or in environmental quality. The importance of taking the own consumption position relative to the average past consumption in the economy into account when addressing the relationship between status and environmental externalities was already emphasized by Ng and Wang (1993), who discuss the relationship between relative income (status) and environmental deterioration generated from over-consumption. Howarth (1996, 2006) and Wendner (2003, 2005) examine the relationship between status impacts and the design of optimal environmental policies. These papers suggest that status desire causes environmental degradation. Brekke et al. (2002) estimate the Hirsch (1976) hypothesis, i. e. status desire enhances consumption at the cost of environmental deterioration. They show that this only remains true when status is represented as the difference between one's agent consumption and the average consumption of society, and if status and non-status goods are poor substitutes. Long and Wang (2009) focus on renewable resource extraction by a finite number of status seeking individuals who interact strategically. They show that status seeking decreases society's growth rate. Alvarez-Cuadrado and Long (2011) show that since status-seeking households overvalue consumption, their eagerness to gain further consumption is higher than the efficient level. Therefore, they over-exploit resources, generating a steady-state stock level that is lower than the efficient level. Second, even when the effort is costless, consumption externalities might interfere with the enthusiasm to shift consumption through time, generating an inefficient path of extraction. This is dynamic distortion. Eckerstorfer and Wendner (2013) study optimal linear commodity taxation in a two-good economy, where one of the goods is positional and the other non-positional. Their main contribution is to explore tax policy consequences of non-atmospheric (agents differ in their contribution to the externality) and asymmetric consumption externalities and to examine the joint tax policy implications of relative consumption concerns and inequality-aversion. Aronsson and Johansson-Stenman (2014) examine the optimal provision of state variable public goods by taking global climate as an example in a setting where individuals are concerned by relative consumption. Goerke and Hellesheim (2013) conclude that agents under certain conditions supply more labor if they are concerned with their status than they would in an undistorted economy without relative concerns. Bouché (2017) focuses on the analysis of the optimal allocation and its decentralization by means of an appropriate tax policy. She finds that a sufficiently high social discount factor is important to prevent possible local oscillations. Besides, investment should either be subsidized or taxed contingent on the magnitude of environmental degradation and aspirations while maintenance investment should always be subsidized. Bouché and de Miguel (2019) explore the repercussions of assuming that the intensity of aspirations is endogenous. They show that such a change in the intensity of aspirations induce a U-shaped relationship between capital accumulation and environmental quality.

Our paper can be linked to models that have brought in external habitimpacts in dynamic models in relation to environmental issues. We can refer to the works of Wendner (2003, 2005) and Brekke and Howarth (2003), who examine the consequences of environmental externalities when relative consumption is concerned. In the present paper, we choose to explore the consequence of environmental externalities when external habits are brought in the utility function such that the cohort size matters. We put into consideration the question of whether the status seeking behavior leads individuals to "over-consume", and thus to overuse the environment relatively to a social optimum. Our main contribution is to formalize, in an overlapping generations framework of John and Pecchenino (1994), a model in which agents exhibit external habits in consumption. The agents are subject to environmental constraints in which consumption from both young and old generations negatively influence the environmental quality which can be at least partially ameliorated by maintenance spending. We focus particularly on the impact of external habits on the capital and the environment on the laissez-faire equilibrium.

This paper is organized as follows. In Section 2, we introduce the model. Section 3 outlines the optimization problem. Section 4 characterizes the equilibrium. In Section 5, we sketch the steady state. In Section 6, we provide a numerical analysis. Section 7 concludes the study.

\section{The Model}

An overlapping generations model offers the framework for the analysis. The motivation for using this kind of model for analyzing an environmental externality follows from the fact that economic activities of a generation born at time $t$ generate environmental damage not only in periodt, but also in all future periods $t+1, t+2, \ldots ., t+n$.

Nevertheless, if a finitely-lived generation born at $t$ is alive for only $k<n$ periods, it would not consider environmental degradation beyond period $t+k$, that is it does not consider the external costs caused for generations still alive after period $t+k$. Thus, the use of an infinitely-lived individuals' model would obscure the relationship between generations that cause environmental damages and generations that bear the costs of these damages. 
We assume a fully competitive overlapping generations economy where economic activity is operated over infinite discrete time. Agents live two periods. We define by generation $t$ the cohort of agents born at $t$, with $t=1,2,3, \ldots$ Each young generation consists of $L_{t}$ identical individuals (except for their ages). For the purpose of simplicity, we suppose a zero-growth rate of the population. I.e., $L_{t}=L$ for every $t^{1}$ and each young and old generation consists of $L$ individuals.

Each generation lives for two periods, youth, and old age. The generation obtains utility from consumption in both periods and environmental quality in old age. Let $c_{t}^{1}$ denote consumption of generation $t$ in the first period (youth), $c_{t+1}^{2}$ consumption of generation $t$ in the second period (old age). The young generation receives a wage rate $w_{t}$ per unit of labor. This is allocated to consumption $c_{t}^{1}$, savings $s_{t}$ and maintenance investment $m_{t}$. Both savings and gross return on savings $R$ are fully consumed by the old generation. The elderly do not contribute to environmental maintenance since they do not enjoy future environmental improvements. We are not claiming that old people are not interested at all in environmental maintenance, but that they are interested to a smaller extent than the young are.

The individuals' constraints over the two periods can therefore be summarized as follows:

$W_{t}=c_{t}^{1}+s_{t}+m_{t}$,

$c_{t+1}^{2}=R_{t+1} S_{t}$.

These constraints are summarized as the life-cycle budget constraint:

$c_{t}^{1}+c_{t+1}^{2} / R_{t+1}+m_{t}=w_{t}$.

Individuals derive utility not only from their absolute consumption levels and from environmental quality, but also from the status attained by consuming at above-average levels. Hence, seeking status may induce higher consumption levels and thus, relative to a social optimum, overuse of the environment.

The individual's utility $U$ is derived from consumption and environmental quality in the first and second periods. It is twice continuously differentiable, increasing in all arguments and strictly concave, where $U^{\prime}>0$ and $U^{\prime \prime}<0$. Preferences of each individual are defined by the log-linear lifetime utility $U$ :

$U=\operatorname{In} \tilde{c}_{t}^{1}+\operatorname{In} \tilde{c}_{t+1}^{2}+\ln E_{t}+\ln E_{t+1}$.

Each variable of the utility function $\tilde{c}^{1}, \widetilde{c}^{2}$ and $E_{t}$ is discussed afterwards.
In the present analysis, the economy is in front of two types of intergenerational externality. The first one is attributable to external habits as a frame of reference originating in the consumption relative to the average one. The second is attributable to the effect of present consumption decisions on the level of environmental quality enjoyed by upcoming generations. Individuals derive utility not only from environmental quality. They also gain utility from status (external habit stock) which is obtained by a high consumption level relative to average consumption.

Variable $E$ denotes environmental quality, which is an intergenerational public good. As in John and Pecchenino (1994), the index of environmental quality evolves according to the equation:

$E_{t+1}=E_{t}-\beta\left(\sum_{i=1}^{L}\left(c_{t}^{1}\right)^{i}+\sum_{j=1}^{L}\left(c_{t}^{2}\right)^{j}\right)+\delta \sum_{i=1}^{L}\left(m_{t}\right)^{i}$.

The superscripts $i$ and $j$ represent respectively a single individual from young and old generations. $E_{t}$ is the environment quality in period $t, E_{t+1}$ is the environment quality in period $t+1, \beta>0$ stands for the degradation of the environment and $\delta>0$ is the environmental improvement due to the actions of the young at $t$.

This index may incorporate the inverse of the concentration of chlorofluorocarbons in the atmosphere, the inverse of other greenhouse gases, the quality of groundwater, or an index of biodiversity.

We introduce the external habits in consumption following the work of Wendner (2005). The variable $\widetilde{c}_{t}^{1}$ defines effective consumption of a single individual in the first period of life:

$\widetilde{c}_{t}^{1} \equiv c_{t}^{1}-\gamma C_{t}$,

where $C_{\mathrm{t}}$ is the average consumption across all individuals ${ }^{2}$ such that:

$C_{t} \equiv\left(\sum_{i}\left(c_{t}^{1}\right)^{i}+\sum_{j}\left(c_{t}^{2}\right)^{j}\right) /\left(L_{t}+L_{t-1}\right)=\frac{\left(\sum_{i}\left(c_{t}^{1}\right)^{i}+\sum_{j}\left(c_{t}^{2}\right)^{j}\right)}{2 L}$.

In aggregate, if all individuals behave the same way,

$C_{t} \equiv\left(L_{t} c_{t}^{1}+L_{t-1} c_{t}^{2}\right) /\left(L_{t}+L_{t-1}\right)=\left(c_{t}^{1}+c_{t}^{2}\right) / 2$.

\footnotetext{
${ }^{1}$ John et al. (1995) set up a model with environmental externalities and population growth. They state that a higher population growth rate reduces environmental quality per capita but could increase the aggregate quality of the environment.

2 This formulation of status is equal to the keeping up with the Joneses formulation utilized in Ljungqvist and Uhlig (2000).
} 
Individuals take $C_{t}$ as given. Each person's status rises with his own consumption but reduces with the average consumption of society. The parameter $0<\gamma<1$ expresses the desire of households for status. The higher $\gamma$ is, the younger individuals care for status and for the consumption level of their peers.

Variable $\tilde{c}_{t+1}^{2}$ denotes effective consumption of an individual born in $t$ in the second period of life:

$\tilde{c}_{t+1}^{2} \equiv c_{t+1}^{2}-\gamma C_{t+1}$.

Substituting equation (8) into (6) gives

$\tilde{c}_{t}^{1}=\frac{\left.(2-\gamma) c_{t}^{1}-\gamma c_{t}^{2}\right)}{2}$

Similarly, substituting equation (8) into (9) gives

$\tilde{c}_{t+1}^{1}=\frac{\left.(2-\gamma) c_{t}^{2}-\gamma c_{t}^{1}\right)}{2}$

The law of motion of capital is given by the equilibrium relation between savings and investment. As we have assumed full depreciation of capital ${ }^{3}$, net savings determine the capital stock in the next period, as in Diamond (1965). In intensive terms the accumulation rule for capital can be written as

$k_{t+1}=s_{t}$.

The firms are perfectly competitive profit maximizers that produce output using the production function: $F\left(K_{t}, L_{t}\right)=Y_{t}$. The capital stock in period $t$ is $K_{t}$. The employment in period $t$ is $L_{t}$. The level of output in period $t$ is $Y_{t}$. The production function can be written in the intensive form:

$y_{t}=f\left(k_{t}\right)$,

where $y_{t}$ and $k_{t}$ are output and capital per worker respectively, and $f(k) \equiv F(k, 1)$. We suppose that the per capita production function, $f\left(k_{t}\right)$, satisfies the standard neoclassical properties. The production function $f: R_{+} \rightarrow R_{+}$ has the following properties. It is twice continuously differentiable, increasing and strictly concave. In particular, $f^{\prime}\left(k_{t}\right)>0 ; f^{\prime \prime}\left(k_{t}\right)<0 ; k f^{\prime \prime}(k)+f^{\prime}(k)>0$ for every $k>0$. Moreover, we impose that $\lim _{k \rightarrow \infty} f^{\prime}\left(k_{t}\right)=0, \lim _{k \rightarrow 0} f^{\prime}\left(k_{t}\right)=\infty$ and $f(0)=0$.

At each time $t$, the output per unit labour $y_{t}=f\left(k_{t}\right)$ is allocated to maintenance expenditure, consumption, and capital investment.

${ }^{3}$ In the overlapping generations model, since one period is set at least as 25 years long, the assumption of $100 \%$ capital depreciation is realistic.

\section{The Optimization Problem}

Let $t=1$ be the initial period. Individuals from generation $t$ face consumption externalities both when young at $t$ and when old at $t+1$. The externality at $t+1$ is affected by the consumption of other old people at $t+1$, and it is also affected by consumption of the next generation of young people at $t+1$. This creates an intergenerational externality, and it is a potential source of multiplicity of equilibria.

The optimization problem for individuals $i$ of generation $t$ is

$$
\begin{aligned}
\underset{c_{t}^{1 i}, c_{t+1}^{2 i}, m_{t}^{i}, E_{t+1}}{\operatorname{maximize}} & \ln \left[c_{t}^{1 i}-\gamma\left(c_{t}^{1 i}+C_{t}^{-1 i}\right) /(2 L)\right] \\
+ & \ln \left[\left(c_{t+1}^{2 i}-\gamma\left(c_{t+1}^{2 i}+C_{t+1}^{-2 i}\right) /(2 L)\right]+\ln E_{t}+\ln E_{t+1}\right.
\end{aligned}
$$

subject $c_{t}^{1 i}+c_{t+1}^{2 i} / R_{t+1}+m_{t}^{i}=w_{t}$

$E_{t+1}=E_{t}-\beta\left(c_{t}^{1 i}+C_{t}^{-1 i}\right)+\delta\left(m_{t}^{i}+M_{t}^{-i}\right)$

where individual i takes as given $C_{t}^{-1 i}, C_{t+1}^{-2 i}$ and $M_{t}^{-i}$. In equilibrium we must have

$$
\begin{gathered}
C_{t}^{-1 i}=\sum_{j=1}^{L} c_{t}^{1 j}+\sum_{j=1}^{L} c_{t}^{2 j}-c_{t}^{1 i}, t \geq 1 \\
C_{t+1}^{-2 i}=\sum_{j=1}^{L} c_{t+1}^{1 j}+\sum_{j=1}^{L} c_{t+1}^{2 j}-c_{t+1}^{2 i}, t \geq 1 \\
M_{t}^{-i}=\sum_{j=1}^{L} m_{t}^{j}-m_{t}^{i}, t \geq 1 .
\end{gathered}
$$

Use the budget constraint (14) to eliminate $c_{t+1}^{2 i}$ in the objective function, and use the environmental law of motion (15) to eliminate $E_{t+1}$ :

$$
\begin{aligned}
\underset{c_{t}^{1 i}, m_{t}^{i}}{\operatorname{maximize}} \ln \left[\left(1-\frac{\gamma}{2 L}\right) c_{t}^{1 i}-\frac{\gamma}{2 L} C_{t}^{-1 i}\right]+\ln \left[\left(1-\frac{\gamma}{2 L}\right)\right. \\
\\
\left.R_{t+1}\left(w_{t}-m_{t}^{i}-c_{t}^{1 i}\right)-\frac{\gamma}{2 L} C_{t+1}^{-2 i}\right]+\ln E_{t} \\
+\ln \left[E_{t}-\beta\left(c_{t}^{1 i}+C_{t}^{-1 i}\right)+\delta\left(m_{t}^{i}+M_{t}^{-i}\right)\right]
\end{aligned}
$$

For all $t \geq 1$, the first order conditions for interior solutions for $c_{t}^{1 i}$ and $m_{t}^{i}$ respectively are

$$
\begin{aligned}
& 0=\frac{1-\frac{\gamma}{2 L}}{\left(1-\frac{\gamma}{2 L}\right) c_{t}^{1 i}-\frac{\gamma}{2 L} C_{t}^{-1 i}}-\frac{\left(1-\frac{\gamma}{2 L}\right) R_{t+1}}{\left(1-\frac{\gamma}{2 L}\right) c_{t+1}^{2 i}-\frac{\gamma}{2 L} C_{t+1}^{-2 i}}-\frac{\beta}{E_{t+1}}, \\
& 0=\frac{\left(1-\frac{\gamma}{2 L}\right) R_{t+1}}{\left(1-\frac{\gamma}{2 L}\right) c_{t+1}^{2 i}-\frac{\gamma}{2 L} C_{t+1}^{-2 i}}-\frac{\delta}{E_{t+1}} .
\end{aligned}
$$


Subtract (17) from (16) to get

$0=\frac{1-\frac{\gamma}{2 L}}{\left(1-\frac{\gamma}{2 L}\right) c_{t}^{1 i}-\frac{\gamma}{2 L} C_{t}^{-1 i}}-\frac{\delta+\beta}{E_{t+1}}, t \geq 1$.

Equations (17) and (18), together with the budget equation (14) and the environmental law of motion (15), characterize individual behavior.

We can substitute the expressions of $C_{t}^{-1 i}$ and $C_{t+1}^{-2 i}$ into (17) and (18), then add $\left((\delta+\beta) / E_{t+1}\right)$ to both sides of (18) and $\left(\delta / E_{t+1}\right)$ to both sides of (17). Since all individuals within each generation are identical, we can drop the superscripts $i$ and $j$. The result is the following:

$$
\begin{aligned}
& \left(1-\frac{\gamma}{2 L}\right) R_{t+1} \frac{1}{\widetilde{c}_{t+1}^{2}}=\delta \frac{1}{E_{t+1}} \\
& \left(1-\frac{\gamma}{2 L}\right) \frac{1}{\widetilde{c}_{t}^{1}}=(\delta+\beta) \frac{1}{E_{t+1}}
\end{aligned}
$$

Equation (19) shows that generation $t$ chooses savings, equating the marginal rate of substitution between the effective consumption in old age and environmental quality in old age to the marginal rate of transformation, $\delta /\left(\left(1-\frac{\gamma}{2 L}\right) R_{t+1}\right)$. At the utility maximum, a decrease in utility due to falling consumption during old age, $\left(1-\frac{\gamma}{2 L}\right) R_{t+1}$, is equal to an increase in utility due to an increase in maintenance effort, $\delta$.

Equation (20) indicates that generation $t$ chooses consumption when young, equating the marginal rate of substitution between consumption in youth and environmental quality in old age to the marginal rate of transformation, $(\delta+\beta) /\left(1-\frac{\gamma}{2 L}\right)$. At the utility maximum, a decrease in utility due to falling consumption during youth is equal to an increase in utility due to the sum of an increase in maintenance effort, $\delta /\left(1-\frac{\gamma}{2 L}\right)$, and a decrease in a consumption externality, $\beta /\left(1-\frac{\gamma}{2 L}\right)$.

Assuming perfect competition in the factor markets, profit maximization in the choice of labor by firms implies that the marginal product of labor must be equated to the real wage. The marginal product of labor is obtained by noting that $Y_{t}=L_{t} f\left(k_{t}\right)$, so that

$$
\frac{\partial Y_{t}}{\partial L_{t}}=f\left(k_{t}\right)-k_{t} f^{\prime}\left(k_{t}\right)
$$

The optimum choice of labor therefore satisfies

$W_{t}=f\left(k_{t}\right)-k_{t} f^{\prime}\left(k_{t}\right)$,
Similarly, the optimum choice of capital equates the rate of interest to the net marginal product

$R_{t}=f^{\prime}\left(k_{t}\right)$.

\section{Competitive Equilibrium}

A competitive equilibrium for the economy under analysis is a sequence $\left\{c_{t}^{1}, c_{t+1}^{2}, m_{t}, w_{t}, r_{t}, s_{t}, k_{t}, E_{t}\right\}_{t=0}^{\infty}$ such that, given the initial conditions of the state parameters $k_{0}$ and $E_{0}$ : i) firms maximize profits; ii) consumers maximize their utility function; iii) markets clear.

Under the hypothesis that $m>0^{4}$ and by using equation (10), equation (19) can be rewritten as follows

$c_{t}^{1}=\frac{\gamma}{2-\gamma} c_{t}^{2}+\frac{(2 L-\gamma)}{L(2-\gamma)(\delta+\beta)} E_{t+1}$.

By substituting equations (12) and (22) into (2) we obtain

$c_{t+1}^{2}=k_{t+1} f^{\prime}\left(k_{t+1}\right)$.

Under the hypothesis that individuals are identical, we can rewrite (5) as

$E_{t+1}=E_{t}-\beta L\left(c_{t}^{1}+c_{t}^{2}\right)+\delta L m_{t}$.

Environmental quality is influenced by two economic activities: consumption and environmental expenditures. As (25) illustrates, the environmental quality at time $t+1$ is influenced by the consumption of the old individuals born in time $t-1$, i. e. the variable $L c_{t}^{2}$, and by the consumption of the young individuals born in $t, L c_{t}^{15}$. While young individualstake into account the environmental deterioration when old, they do not considerthe degradation of the environment and its effect on the future generations' utility in the periods afterwards. In other words, even though consumption of those now alive generates an environmental externality that affects future generations' utility, this impact is disregarded by current generations.

The environment is positively influenced by the environmental expenditures $L m_{t}$. Nevertheless, while households' efforts decrease the existing stock of waste for themselves and for upcoming generations, the current generation cares only about its own welfare and disregards any benefits provided to its descendants. The assumption $\delta>0$ guarantees that investment in the environment has a positive impact

\footnotetext{
${ }^{4}$ We focus on the case of $m>0$. Notice that there is nothing in the model that prevents the possibility that $m_{t}=0$. For the case $m_{t}=0$ see John and Pecchenino (1994).

${ }^{5}$ We suppose that the pollution coefficient of $c_{t}^{1}$ is the same as that of $c_{t}^{2}$ since these consumption goods are homogeneous.
} 
on environmental quality. The coeficients $\beta$ and $\delta$ are supposed to be time invariant.

By substituting equations (14), (12), (21), (22), (23), (24), and (24) lagged once into (25), we get

$$
\begin{aligned}
E_{t+1}=E_{t} & -\beta L\left(\frac{\gamma}{2-\gamma} k_{t} f^{\prime}\left(k_{t}\right)+\frac{(2 L-\gamma)}{L(2-\gamma)} \frac{1}{(\delta+\beta)} E_{t+1}+k_{t} f^{\prime}\left(k_{t}\right)\right) \\
& +\delta L\left[f\left(k_{t}\right)-k_{t} f^{\prime}\left(k_{t}\right)-\frac{\gamma}{2-\gamma} k_{t} f^{\prime}\left(k_{t}\right)-\frac{(2 L-\gamma)}{L(2-\gamma)} \frac{1}{(\delta+\beta)} E_{t+1}\right. \\
& \left.-k_{t+1}\right] .
\end{aligned}
$$

It reduces to

$$
\begin{aligned}
E_{t+1} & =E_{t}-\beta L\left(\frac{2}{2-\gamma} k_{t} f^{\prime}\left(k_{t}\right)+\frac{(2 L-\gamma)}{L(2-\gamma)} \frac{1}{(\delta+\beta)} E_{t+1}\right) \\
+ & \delta L\left[f\left(k_{t}\right)-\frac{2}{2-\gamma} k_{t} f^{\prime}\left(k_{t}\right)-\frac{(2 L-\gamma)}{L(2-\gamma)} \frac{1}{(\delta+\beta)} E_{t+1}-k_{t+1}\right]
\end{aligned}
$$

By plugging equation (11), equation (19) can be rewritten as follows

$$
\left(1-\frac{\gamma}{2 L}\right) R_{t+1} \frac{2}{(2-\gamma) c_{t+1}^{2}-\gamma c_{t+1}^{1}}=\delta \frac{1}{E_{t+1}} .
$$

By simplifying and rearranging this equation, we obtain

$c_{t+1}^{2}=\frac{2\left(1-\frac{\gamma}{2 L}\right) R_{t+1}}{(2-\gamma) \delta} E_{t+1}+\frac{\gamma}{2-\gamma} c_{t+1}^{1}$.

Substituting equation (23) advanced once into the above equation leads to

$c_{t+1}^{2}=\frac{\left(1-\frac{\gamma}{2 L}\right)}{2(1-\gamma)}\left[\frac{R_{t+1}(2-\gamma)}{\delta} E_{t+1}+\frac{\gamma}{(\delta+\beta)} E_{t+2}\right]$.

Substituting equations (24) and (22) advanced once into the above equation yields

$\left.k_{t+1} f^{\prime}\left(k_{t+1}\right)=\frac{\left(1-\frac{\gamma}{2 L}\right)}{2(1-\gamma)}\left[\frac{f^{\prime}\left(k_{t+1}\right)(2-\gamma)}{\delta} E_{t+1}+\frac{\gamma}{(\delta+\beta)} E_{t+2}\right] .28\right)$

Equations (27) and (28) represent the law of motion for the environment.

\section{Steady State}

Since all parameters are constant in the steady state, time subscripts are eliminated. Let $\bar{k}$ and $\bar{E}$ indicate steady state values.
In steady state, equation (27) becomes

$$
\bar{E}=-\beta L \frac{2}{(2 L-\gamma)} \bar{k} f^{\prime}(\bar{k})+\delta L \frac{(2-\gamma)}{(2 L-\gamma)}\left[f(\bar{k})-\frac{2}{2-\gamma} \bar{k} f^{\prime}(\bar{k})-\bar{k}\right] .
$$

In steady state, equation (28) becomes

$$
\bar{E}=\frac{2(1-\gamma) \delta(\delta+\beta) \bar{k} f^{\prime}(\bar{k})}{\left(1-\frac{\gamma}{2 L}\right)\left[(2-\gamma)(\delta+\beta) f^{\prime}(\bar{k})+\delta \gamma\right]} .
$$

The following analysis describes the comparative static behavior of the steady state of this model.

The differentiation of (29) and (30) taking $\beta$ and $\delta$ as given yields

$\left[\begin{array}{ll}\Omega_{1} & \Omega_{2} \\ \Omega_{3} & \Omega_{4}\end{array}\right]\left[\begin{array}{l}\partial \bar{E} \\ \partial \bar{k}\end{array}\right]=\left[\begin{array}{l}\Omega_{5} \\ \Omega_{6}\end{array}\right] \partial \gamma$

Where:

$\Omega_{1}=1$.

By deriving (29) with respect to $\bar{k}$, we get

$\Omega_{2}=\frac{2 \beta L}{2 L-\gamma}\left(f^{\prime}+\bar{k} f^{\prime \prime}\right)-\frac{\delta L(2-\gamma)}{2 L-\gamma}\left[f^{\prime}-\frac{2}{2-\gamma}\left(f^{\prime}+\bar{k} f^{\prime \prime}\right)-1\right]$.

By simplifying and rearranging $\Omega_{2}$, we obtain

$\Omega_{2}=\frac{2 L}{2 L-\gamma}\left(f^{\prime}+\bar{k} f^{\prime \prime}\right)(\beta+\delta)+\frac{\delta L(2-\gamma)}{2 L-\gamma}\left(1-f^{\prime}\right)$.

For our study we use a Cobb-Douglas function $f(k)=A k^{\alpha}$, where $0<\alpha<1$ is the share of capital in the production process, $A$ is a time-invariant productivity parameter.

Under our assumptions on the parameters and based on the following cases

$\left(\bar{k}=\bar{k}_{\text {min }}, \alpha \rightarrow 0\right) \Rightarrow\left(1-f^{\prime}\right)>0$,

$\left(\bar{k}=\bar{k}_{\text {min }}, \alpha \rightarrow 1\right) \Rightarrow\left(1-f^{\prime}\right)=0$,

$\left(\bar{k}=\bar{k}_{\text {max }}(\bar{k} \gg), \alpha \rightarrow 0\right) \Rightarrow\left(1-f^{\prime}\right)=1$,

$\left(\bar{k}=\bar{k}_{\text {max }}(\bar{k} \gg), \alpha \rightarrow 1\right) \Rightarrow\left(1-f^{\prime}\right)>0$, we conclude that $\Omega_{2}$ is positive for every $(\bar{k}, \alpha)$.

By deriving (30) with respect to $\bar{E}$, we get

$\Omega_{3}=\left(1-\frac{\gamma}{2 L}\right)\left[(2-\gamma)(\delta+\beta) f^{\prime}+\delta \gamma\right]$.

$\Omega_{3}$ is positive given the assumptions on the parameters. 
The expressions of $\Omega_{4}, \Omega_{5}$ and $\Omega_{6}$ may be calculated similarly. We obtain

$\Omega_{4}=\overline{\mathrm{E}}\left(1-\frac{\gamma}{2 L}\right)(2-\gamma)(\delta+\beta) f^{\prime \prime}-2(1-\gamma) \delta(\delta+\beta)\left(f^{\prime}+\bar{k} f^{\prime \prime}\right)$.

$\Omega_{4}$ is negative given the assumptions on the parameters.

$\Omega_{5}=\frac{-2 L}{(2 L-\gamma)^{2}}\left[\delta(L-1)(f-\bar{k})+(\delta+\beta) \bar{k} f^{\prime}\right]$.

Under our assumptions on the parameters and based on the following cases

$\left(\bar{k}=\bar{k}_{\text {min }}, \alpha \rightarrow 0\right) \Rightarrow \Omega_{5}<0$,

$\left(\bar{k}=\bar{k}_{\text {min }}, \alpha \rightarrow 1\right) \Rightarrow \Omega_{5}<0$,

$\left(\bar{k}=\bar{k}_{\max }(\bar{k} \gg), \alpha \rightarrow 1\right) \Rightarrow \Omega_{5}<0$, we conclude that

$\Omega_{5}<0$.

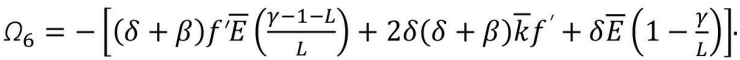

For $\gamma \rightarrow 0$ and from the numerical analysis of the following section, $\Omega_{6}<0$.

For $\gamma \rightarrow 1$ and from the numerical analysis of the following section, $\Omega_{6}<0$.

We conclude that $\Omega_{6}$ is negative.

Consequently, the determinant of the left-hand-side ma$\operatorname{trix}|\Delta|=\Omega_{1} \Omega_{4}-\Omega_{2} \Omega_{3}$ is negative.

\section{The stability properties of the long-run equilibrium}

The stability of the fixed point of the long-run equilibrium can be determined by examining the eigenvalues of the Jacobian matrix $J$. We first set up the Jacobian matrix of partial derivatives.

$J_{(E, k)}=\left[\begin{array}{ll}\frac{\partial E_{t+1}}{\partial E_{t}} & \frac{\partial E_{t+1}}{\partial k_{t}} \\ \frac{\partial k_{t+1}}{\partial E_{t}} & \frac{\partial k_{t+1}}{\partial k_{t}}\end{array}\right] \quad J=\left[\begin{array}{ll}\Omega_{1} & \Omega_{2} \\ \Omega_{3} & \Omega_{4}\end{array}\right]$

Now, we evaluate the Jacobian matrix $J$ at the steady state.

$J_{(\bar{E}, \bar{k})}=A=\left[\begin{array}{ll}\Omega_{1} & \Omega_{2} \\ \Omega_{3} & \Omega_{4}\end{array}\right]$.

The eigenvalues are obtained by solving the characteristic polynomial $\mathrm{P}(\lambda)=\operatorname{det}(\mathrm{A}-\lambda \mathrm{I})=0$

$$
\begin{aligned}
& P(\lambda)=\left|\begin{array}{cc}
\Omega_{1}-\lambda & \Omega_{2} \\
\Omega_{3} & \Omega_{4}-\lambda
\end{array}\right|=0 \\
& P(\lambda)=\left(\Omega_{1}-\lambda\right)\left(\Omega_{4}-\lambda\right)-\Omega_{2} \Omega_{3} \\
& P(\lambda)=\lambda^{2}-\left(\Omega_{1}+\Omega_{4}\right) \lambda+\Omega_{4}-\Omega_{2} \Omega_{3}=0
\end{aligned}
$$

$\lambda_{1}=\frac{\Omega_{1}+\Omega_{4}+\sqrt{\left(\Omega_{1}-\Omega_{4}\right)^{2}+4 \Omega_{2} \Omega_{3}}}{2}$

$\lambda_{2}=\frac{\Omega_{1}+\Omega_{4}-\sqrt{\left(\Omega_{1}-\Omega_{4}\right)^{2}+4 \Omega_{2} \Omega_{3}}}{2}$.

The eigenvalues are then $\lambda_{1}$ and $\lambda_{2}$. The stability properties of the long-run equilibrium can be studied by proving that the partial derivatives have moduli strictly less than one, that is $\lambda_{i} \leq 1$ for all $i$. In our case, we should be able to prove that

$$
\left\{\begin{array}{l}
\left|\frac{\Omega_{1}+\Omega_{4}+\sqrt{\left(\Omega_{1}-\Omega_{4}\right)^{2}+4 \Omega_{2} \Omega_{3}}}{2}\right|<1 \\
\left|\frac{\Omega_{1}+\Omega_{4}-\sqrt{\left(\Omega_{1}-\Omega_{4}\right)^{2}+4 \Omega_{2} \Omega_{3}}}{2}\right|<1
\end{array}\right.
$$

Actually, we have $\lambda_{1}$ positive, hence we can write expression (a) as

$\frac{\Omega_{1}+\Omega_{4}+\sqrt{\left(\Omega_{1}-\Omega_{4}\right)^{2}+4 \Omega_{2} \Omega_{3}}}{2}<1$,

and we have $\lambda_{2}$ negative, hence we can write expression (b) as $\frac{\Omega_{1}+\Omega_{4}-\sqrt{\left(\Omega_{1}-\Omega_{4}\right)^{2}+4 \Omega_{2} \Omega_{3}}}{2}>-1$.

Thus, we obtain the following system of inequalities

$\left\{\begin{array}{l}\frac{\Omega_{1}+\Omega_{4}+\sqrt{\left(\Omega_{1}-\Omega_{4}\right)^{2}+4 \Omega_{2} \Omega_{3}}}{2}<1 \\ \frac{-\Omega_{1}-\Omega_{4}+\sqrt{\left(\Omega_{1}-\Omega_{4}\right)^{2}+4 \Omega_{2} \Omega_{3}}}{2}<1 .\end{array}\right.$

We have $\Omega_{1}=1$. The system reduces to

$\left\{\begin{array}{c}1+\Omega_{4}+\sqrt{\left(1-\Omega_{4}\right)^{2}+4 \Omega_{2} \Omega_{3}}-2<0 \\ -1-\Omega_{4}+\sqrt{\left(1-\Omega_{4}\right)^{2}+4 \Omega_{2} \Omega_{3}}-2<0\end{array}\right.$

and this is true if

$-3+\sqrt{\left(1-\Omega_{4}\right)^{2}+4 \Omega_{2} \Omega_{3}}<\Omega_{4}<1-\sqrt{\left(1-\Omega_{4}\right)^{2}+4 \Omega_{2} \Omega_{3}}$.

Hence, we can conclude that the system converges to a long-run equilibrium which is asymptotically stable if $-3+\sqrt{\left(1-\Omega_{4}\right)^{2}+4 \Omega_{2} \Omega_{3}}<\Omega_{4}<1-\sqrt{\left(1-\Omega_{4}\right)^{2}+4 \Omega_{2} \Omega_{3}}$. 
We next study the effects of external habit formation on the steady state equilibrium level of capital accumulation and environmental quality.

The conditions of the equilibrium characterize (a) two equation(s) system with two unknowns. The equilibrium condition system is a Cramer's system.

Let's note $J=\left[\begin{array}{ll}\Omega_{1} & \Omega_{2} \\ \Omega_{3} & \Omega_{4}\end{array}\right]$ and $P=\left[\begin{array}{l}\Omega_{5} \partial \gamma \\ \Omega_{6} \partial \gamma\end{array}\right]$

This gives $J_{1}=\left[\begin{array}{ll}\Omega_{5} \partial \gamma & \Omega_{2} \\ \Omega_{6} \partial \gamma & \Omega_{4}\end{array}\right]$ and $J_{2}=\left[\begin{array}{ll}\Omega_{1} & \Omega_{5} \partial \gamma \\ \Omega_{3} & \Omega_{6} \partial \gamma\end{array}\right]$

$\partial \bar{k}=\frac{\left|J_{2}\right|}{|\Delta|}=\frac{\left|\Omega_{1} \Omega_{6} \partial \gamma-\Omega_{3} \Omega_{5} \partial \gamma\right|}{|\Delta|}$

$\frac{\partial \bar{k}}{\partial \gamma}=\frac{1}{|\Delta|}\left\{\Omega_{1} \Omega_{6}-\Omega_{3} \Omega_{5}\right\}>0$,

$\partial \bar{E}=\frac{\left|J_{1}\right|}{|\Delta|}=\frac{\left|\Omega_{4} \Omega_{5} \partial \gamma-\Omega_{2} \Omega_{6} \partial \gamma\right|}{|\Delta|}$

$\frac{\partial \bar{E}}{\partial \gamma}=\frac{1}{|\Delta|}\left\{\Omega_{4} \Omega_{5}-\Omega_{2} \Omega_{6}\right\}<0$.

Proposition: Economies with higher external habit stock have worse environmental quality and accumulate more capital in steady state than economies with less external habit stock.

To explicitly understand the results obtained, let us look at the marginal rates of substitution and determinate the status seeking impact on the environment.

$M R S_{m, c^{1}}=\frac{U_{c^{1}}^{\prime}}{U_{m}^{\prime}}=\frac{(1-\gamma / 2 L) U_{1}-\beta U_{3}}{\delta U_{3}} ; M R S_{m, c^{2}}=\frac{(1-\gamma / 2 L) U_{2}}{\delta U_{3}} ;$

$M R S_{c^{2}, c^{1}}=\frac{(1-\gamma / 2 L) U_{1}-\beta U_{3}}{(1-\gamma / 2 L) U_{2}}$

where $U_{1}=\frac{1}{\widetilde{c}_{t}^{1}} ; \quad U_{2}=\frac{1}{\widetilde{c}_{t+1}^{2}}$ and $U_{3}=\frac{1}{E_{t+1}}$.

External habits formation increases $M R S_{m, c^{1}}$. Thereby, $\frac{c^{1}}{m}$ has to rise becoming rational to move expenditures from maintenance to consumption in the first period $c^{1}$, i.e., earning a positive marginal utility of increased consumption early in life and also a positive marginal utility of the higher status while young: $\frac{\partial \tilde{c}^{1}}{\partial c^{1}}=\frac{2-\gamma}{2}>0$. This has a negative effect on the environment. On the other hand, the increase in $c^{1}$ decreases savings resulting in a decline in consumption when old, which implies a positive effect on the environment, but a negative one on the capital. Moreover, external habit formation increases $M R S_{\mathrm{m}, c^{2}}$. Thereby, $\frac{c^{2}}{m}$ has to rise becoming rational to move expenditures from maintenance to consumption in the second period $c^{2}$ i.e., earning a positive marginal utility of increased consumption in the second periodand also a positive marginal utility of the higher status while old: $\frac{\partial \tilde{c}^{2}}{\partial c^{2}}=\frac{2-\gamma}{2}>0$. This has a bad environmental effect but a good effect regarding the capital accumulation. Then again, the presence of external habits in the utility function leads $M R S_{c^{2}, c^{1}}$ to decrease which raises the rate of consumption growth becoming rational to reduce consumption early in life since the marginal status utility when old exceeds the marginal status utility when young. This has a good environmental effect. The decline in $c^{1}$ though, increases savings, which enhances the capital accumulation.

The characterization of the steady state shows that the bad effects of striving for status dominate the good effects, which explains the environment worsening. This result goes in the same direction of that obtained by Wendner (2003, 2005). As regards to the capital accumulation, the good effects dominate the bad ones which lead to capital increasing. This result differs from that achieved by Bouché (2017). She states that the negative effect of aspirations on the steady-state capital stock is due to the deterring effect that aspirations play on savings, and hence on capital accumulation. As for Alonso-Carrera and Bouché (2019), they show that agents that are tempted to take the average consumption of individuals living in the same period as their own aspiration or consumption reference may either rise or reduce the accumulation of capital. The key point would be whether consumers take the consumption of the households belonging to the other living generations as a causal factor of their consumption reference.

The economic intuition behind our result is that: individuals increase their first and second consumption possibilities in the pursuit of improved status, which in turn lead to overconsumption. It follows from the life-cycle budget constraint that the maintenance investment reduces. Therefore, the environment degrades as well according to the equation defining the index of environmental quality. To put it differently, individuals drive utility not only from their absolute consumption levels and from environmental quality, but also from the status realized by consuming at above-average levels. Striving for status, therefore, causes higher consumption levels, and thus, the overuse of the environment relative to a social optimum. It is entirely possible then that one of the reasons behind environmental degradation is people over-consume to continuously keep up with the Jones. De la Croix (1996, p. 91) states that “... aspirations affect savings negatively. When aspirations are low, the adult generation has a sober lifestyle and savings are high. When aspirations are high compared with wage income, adults spend much on consumption to main- 
tain a life standard like the one of their parents and their propensity to save is low."

\section{Numerical Analysis}

In this section, the proposition obtained is not general given that its underlying hypotheses include some restrictive functional form assumptions. Thus, the results from the comparative static behavior of the steady state are complemented with some numerical exercises. That is why we choose some parameter values to illustrate visually the effect of the parameters on the steady state equilibrium. We notice in Figure 1, which illustrates the effect of the cohort size $L$ on the aggregate environmental quality $\bar{E}$ for different values of status desire $\gamma$, an identical behavior of $\bar{E}$ independently from $\gamma$ which gradually decreases from $L=2$ and asymptotically approaches a limit value beyond $L=20$ when $\gamma$ rises. The magnitude of $E_{t}$ is lower when the parameter $\gamma$ comes close to unity $(\gamma=0.99)$.

Figure 1. $L$ effects on $E$ for different values of $\gamma$

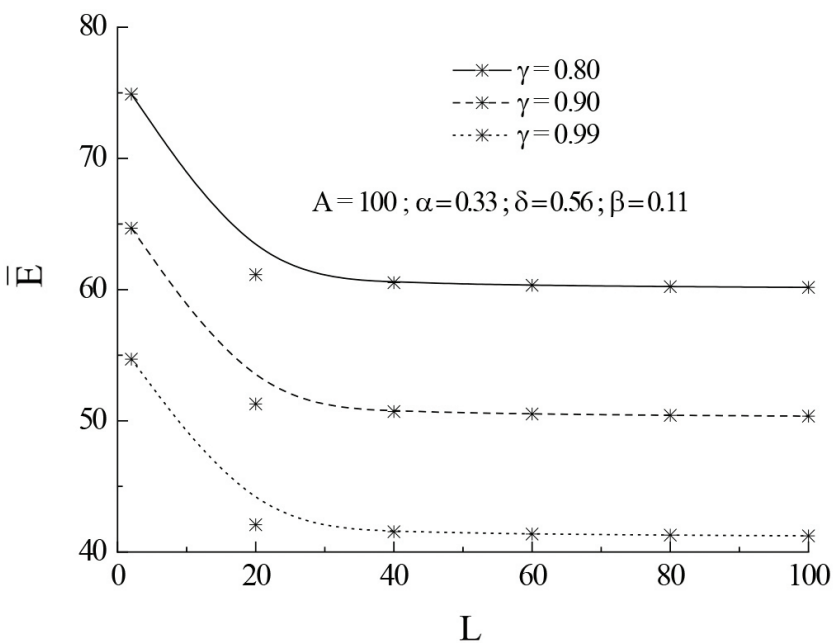

Figure 2(a) shows the evolution of the environmental quality $\bar{E}$ as a function of $\gamma$ for different values of $L$. We see that the curves fall off dramatically with increasing $\gamma$. This decrease starts from a common value of $\bar{E}$ equal to 79 for $\gamma=0$. When $\gamma>0$, the curves disperse, and the reduction gap becomes more and more important when $\gamma$ approaches unity. In this situation, $\bar{E}$ is influenced by $L$ and its lowest magnitude of 31.6 is obtained for a large value of $L$ equal to 100 . As for the impact of $\gamma$ on $\bar{E}$ for various values of $\delta$, we find that the economies have lower levels of $E_{t}$ as $\gamma$ increases and this environment worsening is more important when $\delta=0.6$. The amplitude of $\bar{E}$ is wider for $\gamma=0$ and $\delta=0.6$. Its value is 64 . When $\gamma=0$, the difference between
Figure 2. $\gamma$ effects on $E$ for different values of $L(\mathrm{a}), \delta$ (b), and $\beta$ (c)

a)

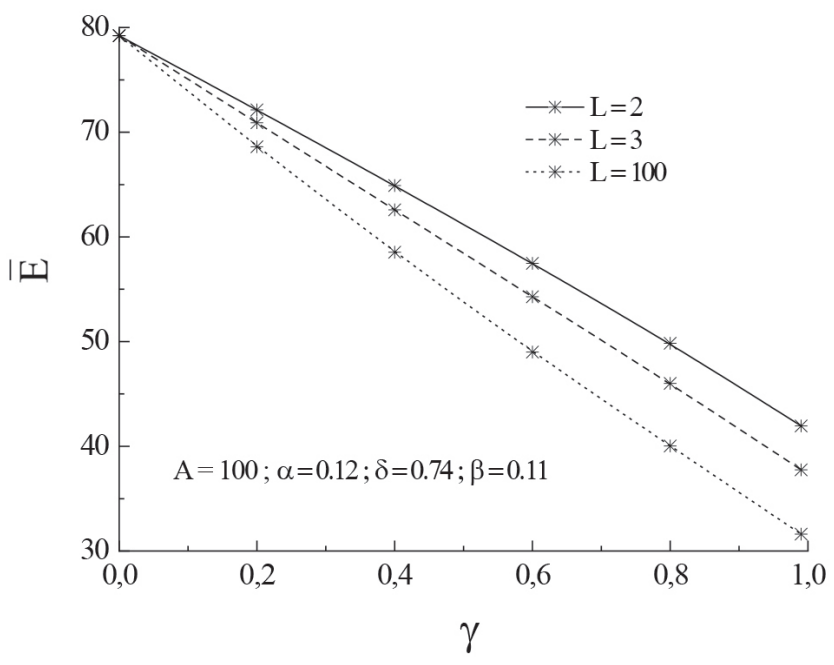

b)

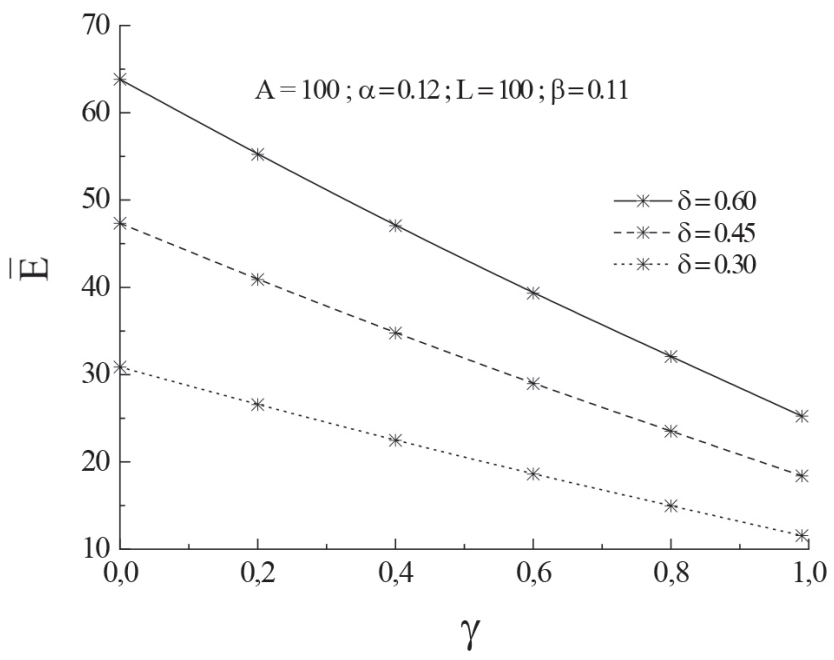

c)

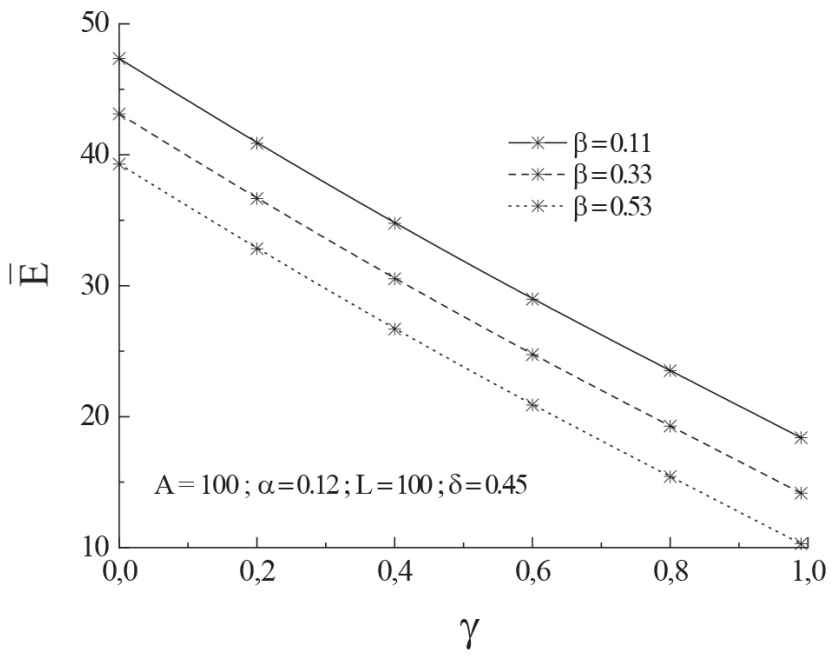


the values of $\bar{E}$ for each $\delta$ is 17 . When $\gamma$ increases, this difference tends to decrease and becomes practically the same when $\gamma$ comes near unity (as shown in Figure 2(b)). Figure 2(c) represents the influence of $\gamma$ on $\bar{E}$ for different values of $\beta$.

We note a similar behavior of $\bar{E}$ which quickly declines with increasing $\gamma . \bar{E}$ is large for $\gamma=0$ and $\beta=0.11$. Its value is 47.3. We also remark that for each specific value of $\gamma$, the difference between the values of $\bar{E}$ is practically the same. Inversely to the evolution of the environmental quality,an opposite behavior is detected as regards the repercussion of the cohort size on the capital accumulation $\bar{k}$ for different values of status desire. It gradually increases from $L=2$ and asymptotically approaches saturation beyond $L=20$. The large effect of $\bar{k}$ at saturation ( $\bar{k}=99$ ) is obtained for $\gamma=0.95$ (Figure 3).

Figure 3. $L$ effects on $k$ for different values of $\gamma$

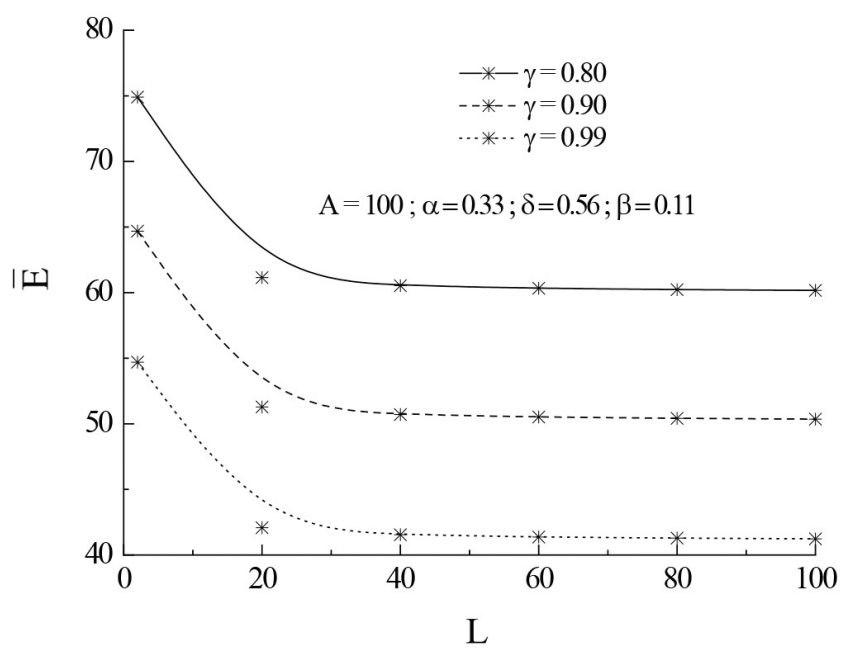

Figure 4 (a), (b) and (c) contain information on how, for different values of $L, \delta$ and $\beta$ respectively, influences $\bar{k}$. We note an identical behavior in the evolutions which indicates the influence of $\gamma$ beyond 0.8. The curves increase rapidly to reach their maximums when $\gamma$ tends towards 1 . The amplitude of $k_{t}$ becomes larger and larger by reducing the values of $\delta$ and $\beta: \bar{k}=93$ for $\beta=0.3$ and $\bar{k}=97.4$ for $\delta=0.3$; and by increasing the value of $L$ : a large value of $L(L=100)$ gives the largest value of $\bar{k}$ of 94.4 when $\gamma$ approaches unity.
Figure 4. $\gamma$ effects on $k$ for different values of $L(\mathrm{a}), \delta$ (b), and $\beta(\mathrm{c})$.

a)

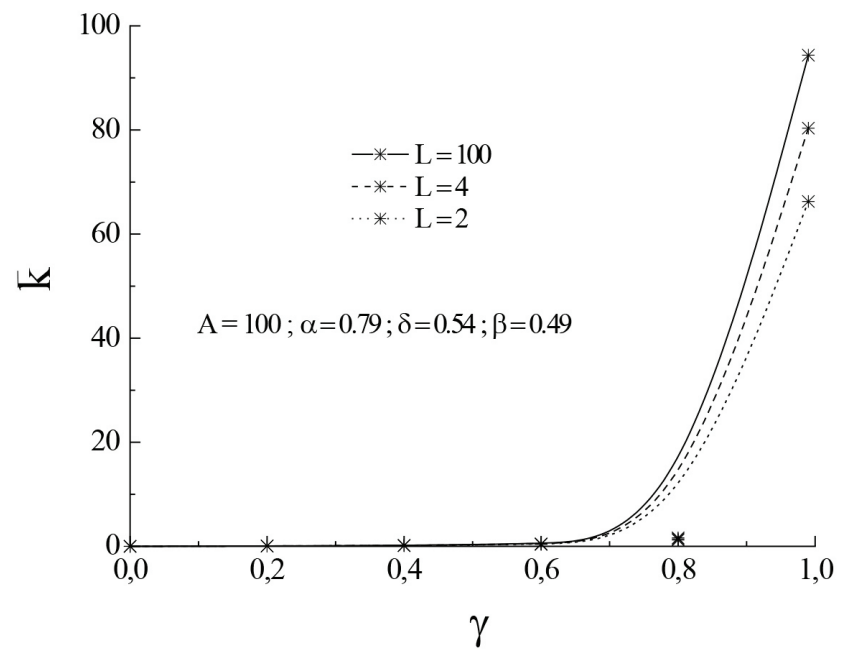

b)

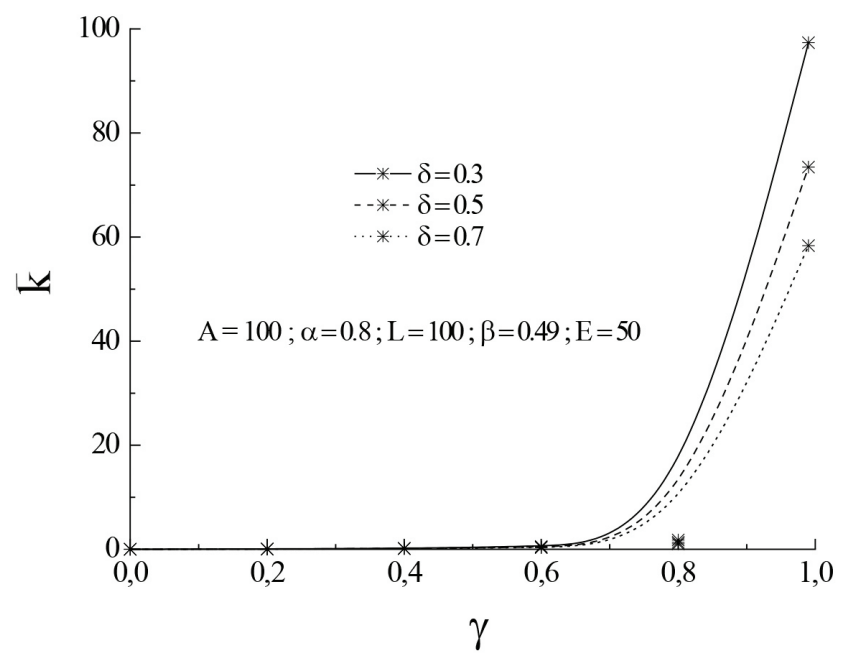

c)

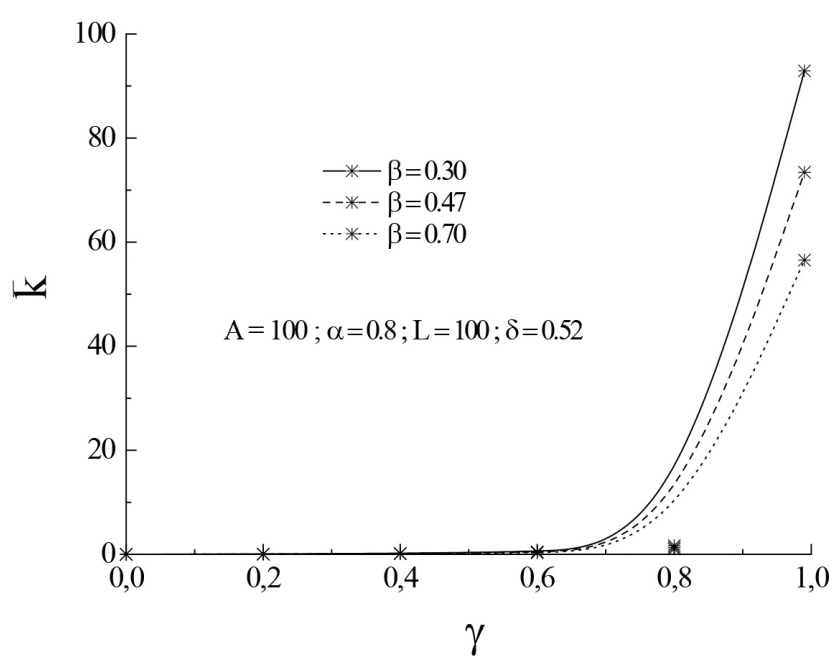




\section{Conclusion}

Since individuals are finitely lived agents in an OLG economy, their consumption has external environmental costs for other individuals. Furthermore, external habits impacts constitute another externality. We consider an overlapping generations model with external habits in consumption and the presence of environmental quali- ty. We focus particularly on the impact of the desire to "keeping up with the Jones" on the capital and the environmental quality in the laissez-faire equilibrium via a comparative statics' analysis. We concluded that economies characterized by a higher level of status desire accumulate more capital and have lower environmental quality standards than economies with less status desire when the cohort size is large.

\section{References}

Alonso-Carrera,J., \&Bouché, S. (2019). Capital accumulation when consumers are tempted by others consumption experience. Oxford Economic Papers, 72(3), 804-828. doi:10.1093/oep/gpz046

Alvarez-Cuadrado, F., \& Long, N. V. (2011). Relative consumption and renewable resource extraction under alternative property-rights regimes. Resource and Energy Economics,33(4), 1028-1053. doi:10.1016/j.reseneeco.2010.09.003

Aronsson, T., \& Johansson-Stenman, O. (2014). State-variable public goods and social comparisons. Journal of Environmental Economics and Management, 68(2), 390-410. doi:10.1016/j.jeem.2014.07.001

Becker, G., \& Mulligan, C. (1997). The endogenous determination of time preference. Quarterly Journal of Economics, 112(3), 729758.Retrieved from http://www.jstor.org/stable/2951254

Bouché, S. (2017). Aspirations, environmental quality and optimal tax policy. ECOBAS Working Papers, 2016-21.

Bouché, S., \&de Miguel, C. (2019). Endogenous aspirations, growth and the rise of environmental concerns. Energy Economics, 84(S1). doi:10.1016/j.eneco.2019.104526

Brekke, K. A., \& Howarth, R. B. (2003). Status, growth, and the environment: goods as symbols in applied welfare economics. Edward Elgar Publishing, Cheltenham.

Brekke, K. A., Howarth, R. B. \& Nyborg, K. (2003). Status-seeking and material affluence: evaluating the Hirsch hypothesis. Ecological Economics, 45(1), 29-39. doi:10.1016/S0921-8009(02)00262-8

de la Croix, D. (1996). The dynamics of bequeathed tastes. Economics Letters,53(1), 89-96. doi:10.1016/S0165-1765(96)00888-9

de la Croix, D., \& Michel, P. (1998). Optimal growth when tastes are inherited. Journal of Economic Dynamics and Control, 23(4), 519-537.doi:10.1016/S0165-1889(98)00028-1

Diamond, P. A. (1965). National debt in the neoclassical growth model. American Economic Review, 55, 279-293. Retrieved from: https://www.aeaweb.org/journals/aer

Eckerstorfer, P., \& Wendner, R. (2013). Asymmetric and non-atmospheric consumption externalities, and efficient consumption taxation. Journal of Public Economics, 106, 42 -56. doi:10.1016/j.jpubeco.2013.07.003

Goerke, L., \& Hellesheim, I. (2013). Relative consumption, working time, and trade unions. Labour Economics, 24, 170-179. doi:10.1016/j.labeco.2013.08.002

Hirsch, F. (1976). The social limits to growth. Cambridge, Mass.: Harvard University Press.

Howarth, R. B. (1996). Status effects and environmental externalities. Ecological Economics, 16(1), 25-34. doi:10.1016/09218009(95)00076-3

Howarth, R. B. (2006). Optimal environmental taxes under relative consumption effects. Ecological Economics, 58(1), 209-219. doi:10.1016/j.ecolecon.2005.07.007

Huang, K.X.D., Liu, Z. \& Zhu, J.Q. (2015). Temptation and self-control: some evidence and applications. Journal of Money, Credit, and Banking, 47, 581-615. doi:10.1111/jmcb.12222

John, A., \& Pecchenino, R. (1994). An overlapping generations model of growth and the environment. The Economic Journal, 104(427), 1393-1410. doi:10.2307/2235455

John, A., Pecchenino R., Schimmelpfennig, D \& Schreft, S. (1995). Short-lived agents and the long-lived environment. Journal of Public Economics, 58(1), 127-141. doi:10.1016/0047-2727(94)01459-2

Ljungqvist, L., \& Uhlig, H. (2000). Tax policy and aggregate demand management under catching up with the Joneses. American Economic Review, 90(3), 356-366. doi:10.1257/aer.90.3.356

Long, N. V., \& Wang, S. (2009). Resource grabbing by status-conscious agents. Journal of Development Economics, 89(1), 39-50. doi:10.1016/j.jdeveco.2008.09.005 
$\mathrm{Ng}$, Y. K., \& Wang, J. (1993). Relative income, aspiration, environmental quality, individual and political myopia: why may the rat race for material growth be welfare reducing? Mathematical Social Sciences, 26(1), 3-23. doi:10.1016/0165-4896(93)90008-7

Wendner, R. (2003). Status, environmental externality, and optimal tax programs. Economics Bulletin, 8(5), 1-10. Retrieved from http:// www.accessecon.com/pubs/eb/

Wendner, R. (2005). Frames of reference, the environment, and efficient taxation. Economics of Governance, 6(1), 13-31. doi:10.1007/ s10101-004-0086-6

\section{Zunanje oblikovanje navad in okolje}

\section{Izvleček}

Pričujoči prispevek predstavlja standardni model prekrivajočih se generacij z zunanjim oblikovanjem navad in kakovostjo okolja v funkciji koristnosti. Glavni cilj prispevka je preučiti vpliv zunanje oblikovanih navad na akumulacijo kapitala in vpliv kakovosti okolja na medčasovno konkurenčno ravnovesje. Opazimo, da v primeru velike kohorte težnja po boljšem statusu privede do poslabšanja kakovosti okolja in povečanja kapitala.

Ključne besede: zunanje oblikovane navade, prekrivajoče se generacije, kakovost okolja 